Research

Open Access

\title{
Mild therapeutic hypothermia shortens intensive care unit stay of survivors after out-of-hospital cardiac arrest compared to historical controls
}

\author{
Christian Storm, Ingo Steffen, Joerg C Schefold, Anne Krueger, Michael Oppert, Achim Jörres and \\ Dietrich Hasper
}

\begin{abstract}
Charité Universitätsmedizin Berlin, Campus Virchow-Klinikum, Department of Nephrology and Medical Intensive Care Medicine, Augustenburger Platz 1, 13353 Berlin, Germany

Corresponding author: Dietrich Hasper, dietrich.hasper@charite.de

Received: 7 Apr 2008 Revisions requested: 8 May 2008 Revisions received: 28 May 2008 Accepted: 14 Jun 2008 Published: 14 Jun 2008

Critical Care 2008, 12:R78 (doi:10.1186/cc6925)

This article is online at: http://ccforum.com/content/12/3/R78

(c) 2008 Storm et al.; licensee BioMed Central Ltd.

This is an open access article distributed under the terms of the Creative Commons Attribution License (http://creativecommons.org/licenses/by/2.0), which permits unrestricted use, distribution, and reproduction in any medium, provided the original work is properly cited.
\end{abstract}

\begin{abstract}
Introduction Persistent coma is a common finding after cardiac arrest and has profound ethical and economic implications. Evidence suggests that therapeutic hypothermia improves neurological outcome in these patients. In this analysis, we investigate whether therapeutic hypothermia influences the length of intensive care unit (ICU) stay and ventilator time in patients surviving out-of-hospital cardiac arrest.
\end{abstract}

Methods A prospective observational study with historical controls was conducted at our medical ICU. Fifty-two consecutive patients (median age 62.6 years, 43 males, 34 ventricular fibrillation) submitted to therapeutic hypothermia after out-of-hospital cardiac arrest were included. They were compared with a historical cohort $(n=74$, median age 63.8 years, 53 males, 43 ventricular fibrillation) treated in the era prior to hypothermia treatment. All patients received the same standard of care. Neurological outcome was assessed using the Pittsburgh cerebral performance category (CPC) score. Univariate analyses and multiple regression models were used.
Results In survivors, therapeutic hypothermia and baseline disease severity (Acute Physiology and Chronic Health Evaluation II [APACHE II] score) were both found to significantly influence ICU stay and ventilator time (all $P<0.01$ ). ICU stay was shorter in survivors receiving therapeutic hypothermia (median 14 days [interquartile range (IOR) 8 to 26] versus 21 days [IQR 15 to 30 ] in the control group; $P=0.017$ ). ICU length of stay and time on ventilator were prolonged in patients with CPC 3 or 4 compared with patients with CPC 1 or $2(P=0.003$ and $P=0.034$, respectively). Kaplan-Meier analysis showed improved probability for 1 -year survival in the hypothermia group compared with the controls (log-rank test $P=0.013$ ).

Conclusion Therapeutic hypothermia was found to significantly shorten ICU stay and time of mechanical ventilation in survivors after out-of-hospital cardiac arrest. Moreover, profound improvements in both neurological outcome and 1-year survival were observed.

\section{Introduction}

Persistent coma is a common finding after cardiac arrest and has profound ethical and economic implications. In a significant proportion of patients, neurological status rather than specific treatment of the underlying disease affects the outcome after cardiac arrest [1]. Recent randomized controlled trials have demonstrated that therapeutic hypothermia is highly effective in improving the neurological outcome in patients after cardiac arrest [2,3]. In 2003, the International Liaison Committee on Resuscitation (ILCOR) recommended this treatment for all comatose survivors of out-of-hospital cardiac arrest due to ventricular fibrillation [4]. Although only a minority of such patients are currently treated with therapeutic hypothermia [5,6], recent efforts aim to implement therapeutic hypothermia as a routine procedure in patients after cardiac arrest [7].

The optimal method for controlled and safe application of therapeutic hypothermia is still under debate [8,9]. For intravascular cooling devices as well as for device-controlled surface

APACHE II = Acute Physiology and Chronic Health Evaluation II; Cl = confidence interval; CPC = cerebral performance category; CPR = cardiopulmonary resuscitation; ICU = intensive care unit; ILCOR = International Liaison Committee on Resuscitation; IQR = interquartile range; LOS = length of stay; MICU = medical intensive care unit; ROSC = return of spontaneous circulation. 
cooling methods, the efficacy has been demonstrated in different trials [10-13]. Of course, other cooling methods like crushed-ice, towels pre-soaked in ice water, or simple cooling blankets may be very effective as well but the temperature range is more difficult to control $[14,15]$. For out-of-hospital cooling, new devices and methods for fast induction of hypothermia are of increasing importance [16,17]. However, using advanced cooling methods, equipment, and manpower required for the application of therapeutic hypothermia generates higher treatment costs. Length of intensive care unit stay (ICU LOS) has been identified as a major determinant of total treatment costs after survived cardiac arrest [18]. Therefore, it was investigated whether therapeutic hypothermia influences ICU LOS and time of mechanical ventilation in patients after out-of-hospital cardiac arrest.

\section{Materials and methods}

The study protocol was approved by the local ethics committee on human research. The need for informed patient consent was waived by the committee. We conducted our study in an urban area with a two-tiered medical emergency system: basic life support, including automated defibrillation, is offered by ambulances, and advanced life support procedures were performed by qualified emergency physicians at the mobile ICU. All patients with cardiac arrest and return of spontaneous circulation (ROSC) in the field were directly admitted to our medical ICU (MICU). Pre-hospital cooling procedures were not applied during the study period.

Between January 2006 and January 2007, a total of 52 patients were admitted to our MICU after out-of-hospital cardiac arrest. All patients received therapeutic hypothermia according to the current ILCOR recommendations. A historical control group in the era prior to hypothermia treatment was identified in a cohort of 74 patients admitted to our MICU between 2003 and 2005 after out-of-hospital cardiac arrest. Detailed characteristics for all study patients are presented in Table 1.

Therapeutic hypothermia was initiated after admission with an intravenous infusion of cold saline $\left(4^{\circ} \mathrm{C}, 1,000\right.$ to $1,500 \mathrm{~mL}$ bolus) followed by surface cooling with commercially available non-invasive devices (CritiCool ${ }^{\circledR}$; MTRE, Yavne, Rehovot, Israel, or ArcticSun2000 ${ }^{\circledR}$; Medivance, Inc., Louisville, CO, USA). After the start of cooling, the target temperature of $33^{\circ} \mathrm{C}$ was reached in a range of 180 to 300 minutes and maintained for 24 hours. Re-warming was performed at a rate of $0.25^{\circ} \mathrm{C}$ per hour. Intravenous sedation was induced in all patients by a combination of midazolam $(0.125 \mathrm{mg} / \mathrm{kg}$ per hour) and fentanyl (0.002 mg/kg per hour) with dose adjustment as needed. Patients undergoing hypothermia received muscle relaxation with repetitive pancuronium $(0.1 \mathrm{mg} / \mathrm{kg})$ administration in order to prevent shivering. All patients completed therapeutic hypothermia without complications or overcooling. With the exception of therapeutic hypothermia, there was no further dif- ference in the standard of intensive care treatment between the two groups. To discover early-onset infection and pneumonia, laboratory markers of systemic inflammation (c-reactive protein/leukocyte count) and radiological findings of pneumonia in chest $x$-ray were analyzed on day 3 . Neurological outcome was assessed at the time of discharge from the ICU according to the Pittsburgh cerebral performance category (CPC) score [19]. CPC 1 and 2 were classified as a favorable neurological outcome, whereas CPC 3 and 4 were regarded as an unfavorable outcome.

The SPSS software (version 13.0; SPSS Inc., Chicago, IL, USA) and R (version 2.4.1; The R Foundation for Statistical Computing) were used for statistical analysis. Descriptive parameters are presented as median and interquartile range (IOR) (25th to 75th percentiles). Univariate analysis of differences between hypothermia patients and the control group was performed by using the Mann-Whitney $U$ test for non-parametric unpaired data and the Fisher exact test for dichotomous variables. Multiple regression analysis was used to adjust for confounders and to analyze the association of one dependent and several independent variables. The general linear start model includes all independent variables, whereas the final model contains only predictive factors after using the automatic method of stepwise backward selection. Survival data were analyzed by the Kaplan-Meier method, and comparison between groups was performed by the log-rank test.

\section{Results}

\section{Univariate analysis}

Results of univariate analysis of all patients $(n=126)$ are presented in Table 1. Concerning age $(P=0.776)$ and gender $(P$ $=0.221$ ), no significant differences were observed between patients in the hypothermia group and the control group. However, APACHE II (Acute Physiology and Chronic Health Evaluation II) score on admission was significantly lower in the control group $(P=0.015)$. No significant differences were calculated concerning the first documented rhythm $(P=0.523)$, dosage of epinephrine during resuscitation $(P=0.106)$, and time to ROSC $(P=0.230)$. Patients with initial ventricular fibrillation were classified as primary shockable rhythm, whereas patients with asystole and pulseless electrical activity were classified as primary non-shockable rhythm.

Univariate analysis of ICU LOS for all patients (dead and alive) showed no significant difference between the two groups $(P$ $=0.947$ ). However, if only survivors were analyzed, ICU LOS was significantly lower in the hypothermia group (median 14 days [IOR 8 to 26] versus 21 days [IOR 15 to 30 ]; $P=0.017$ ) (Figure 1). In contrast to this finding, there was no statistically significant difference regarding ICU LOS in patients who died during ICU stay (median 9 days [IOR 6 to 22] for the hypothermia group and 7 days [IQR 5 to 10 ] for the control group; $P=$ 0.250 ). 
Table 1

\begin{tabular}{|c|c|c|c|}
\hline & $\begin{array}{l}\text { Control } \\
(n=74)\end{array}$ & $\begin{array}{l}\text { Hypothermia } \\
\quad(n=52)\end{array}$ & $P$ value \\
\hline Age, years & $63.8(52.8-72.0)$ & $62.6(50.7-71.4)$ & 0.776 \\
\hline \multicolumn{4}{|l|}{ Gender } \\
\hline Female & $21(28.4)$ & $9(17.3)$ & 0.221 \\
\hline Male & $53(71.6)$ & $43(82.7)$ & \\
\hline APACHE II score & $25.0(20.0-30.0)$ & $30.5(22.5-33.0)$ & 0.015 \\
\hline \multicolumn{4}{|l|}{ Cardiac arrest } \\
\hline Shockable rhythm & $43(58.1)$ & $34(65.4)$ & 0.523 \\
\hline Non-shockable rhythm & $31(41.9)$ & $18(34.6)$ & \\
\hline \multicolumn{4}{|l|}{ Cause of cardiac arrest } \\
\hline Acute myocardial infarction & $47(63.5)$ & $31(59.6)$ & \\
\hline Primary arrhythmia & $12(16.2)$ & $13(25)$ & \\
\hline Respiratory & $12(16.2)$ & $8(15.4)$ & \\
\hline Other & $3(4.1)$ & 0 & \\
\hline \multicolumn{4}{|l|}{ Bystander CPR } \\
\hline Yes & $12(16.2)$ & $16(30.8)$ & 0.086 \\
\hline No & $62(83.8)$ & $36(69.2)$ & \\
\hline Time to ROSC, minutes & $20(18-25)$ & $20(14-22)$ & 0.230 \\
\hline Total epinephrine dose, mg & $3.0(2.0-4.0)$ & $2.75(0.8-3.1)$ & 0.106 \\
\hline \multicolumn{4}{|l|}{ Length of ICU stay, days } \\
\hline All patients & $15(7-26)$ & $13(8-26)$ & 0.947 \\
\hline Non-survivors & $7(5-10)$ & $9(6-22)$ & 0.259 \\
\hline Survivors & $21(15-30)$ & $14(8-26)$ & 0.017 \\
\hline \multicolumn{4}{|l|}{ Time on ventilator, hours } \\
\hline All patients & $217(139-353)$ & $220(124-428)$ & 1 \\
\hline Non-survivors & $165(104-210)$ & $221(133-365)$ & 0.219 \\
\hline Survivors & $328(208-461)$ & $219(125-447)$ & 0.113 \\
\hline Leukocytes at day $3, / \mathrm{nL}$ & $11.0(8.7-13.6)$ & $12.2(8.3-14.1)$ & 0.91 \\
\hline C-reactive protein at day $3, \mathrm{mg} / \mathrm{dL}$ & $12.7(7.5-16.0)$ & $14.5(8.7-21.1)$ & 0.33 \\
\hline Radiological signs of pneumonia & $8(10.8)$ & $10(19.2)$ & 0.205 \\
\hline \multicolumn{4}{|l|}{$\mathrm{CPC}$ at ICU discharge } \\
\hline 1 - good recovery & $8(10.8)$ & $22(42.3)$ & \\
\hline 2 - moderate disability & $9(12.2)$ & $10(19.2)$ & \\
\hline 3 - severe disability & $3(4.1)$ & $2(3.8)$ & \\
\hline 4 - vegetative state & $23(31.1)$ & $3(5.8)$ & \\
\hline 5 - death & $31(41.9)$ & $15(28.8)$ & \\
\hline \multicolumn{4}{|l|}{ CPC $1-2$ versus $3-5$} \\
\hline CPC 1-2 & $17(23.0)$ & $32(61.5)$ & $<0.001$ \\
\hline
\end{tabular}


Table 1 (Continued)

Baseline characteristics of the patient population and results of the univariate analysis

$\begin{array}{lll}\text { CPC } 3-5 & 57(77.0) & 20(38.5) \\ \text { Died during hospital stay } & & 15(28.8) \\ \text { Yes } & 31(41.9) & 37(71.2)\end{array}$

Data are presented as medians (25th and 75th percentiles) or as absolute numbers (relative frequencies). APACHE II, Acute Physiology and Chronic Health Evaluation II; CPC, cerebral performance category; CPR, cardiopulmonary resuscitation; ICU, intensive care unit; ROSC, return of spontaneous circulation.

Univariate analysis of ventilator time revealed no significant difference for all patients $(P=1)$. Median ventilator time was lower in the subgroup of survivors treated with hypothermia, although the difference was not statistically significant (219 hours [IQR 125 to 447] for the hypothermia group versus 328 hours [IQR 208 to 461] for the control group; $P=0.113$ ) (Figure 1). Also, there was no statistically significant difference in ventilator time in the subgroup of non-survivors (221 hours [IOR 133 to 365] for the hypothermia group and 165 hours [IOR 104 to 210] for the control group; $P=0.219$ ).

C-reactive protein, leukocyte count, and radiological diagnosis of early-onset pneumonia on day 3 were not statistically different between the groups (Table 1). With regard to the neurological outcome, both ICU LOS and time on ventilator were significantly longer in patients with a CPC 3 or 4 compared with patients with CPC 1 or $2(P=0.003$ for LOS and $P=$ 0.034 for ventilator time) (Figure 2). Hypothermia treatment was associated with significantly improved neurological out- come assessed by CPC 1 or 2 versus 3 or $4(P<0.001)$. The results of the univariate analysis are summarized in Table 1.

\section{Multivariate analysis}

As univariate analysis showed significant differences between the hypothermia and the control group, an adjustment for confounders was performed. To this end, ICU LOS and respirator time were analyzed with the multivariate regression model, including gender, age, APACHE II score, bystander cardiopulmonary resuscitation (CPR), time to ROSC, initial rhythm, and mild therapeutic hypothermia treatment as independent factors. The final model for ICU LOS in the subgroup of survivors identified a low APACHE II score $(P=0.006)$ and hypothermia treatment $(P=0.004)$ as independent predictors of shorter ICU LOS.

Likewise, multivariate analysis in the subgroup of survivors identified APACHE II score $(P=0.009)$ and hypothermia treatment $(P=0.026)$ as independent predictors of shorter

Figure 1
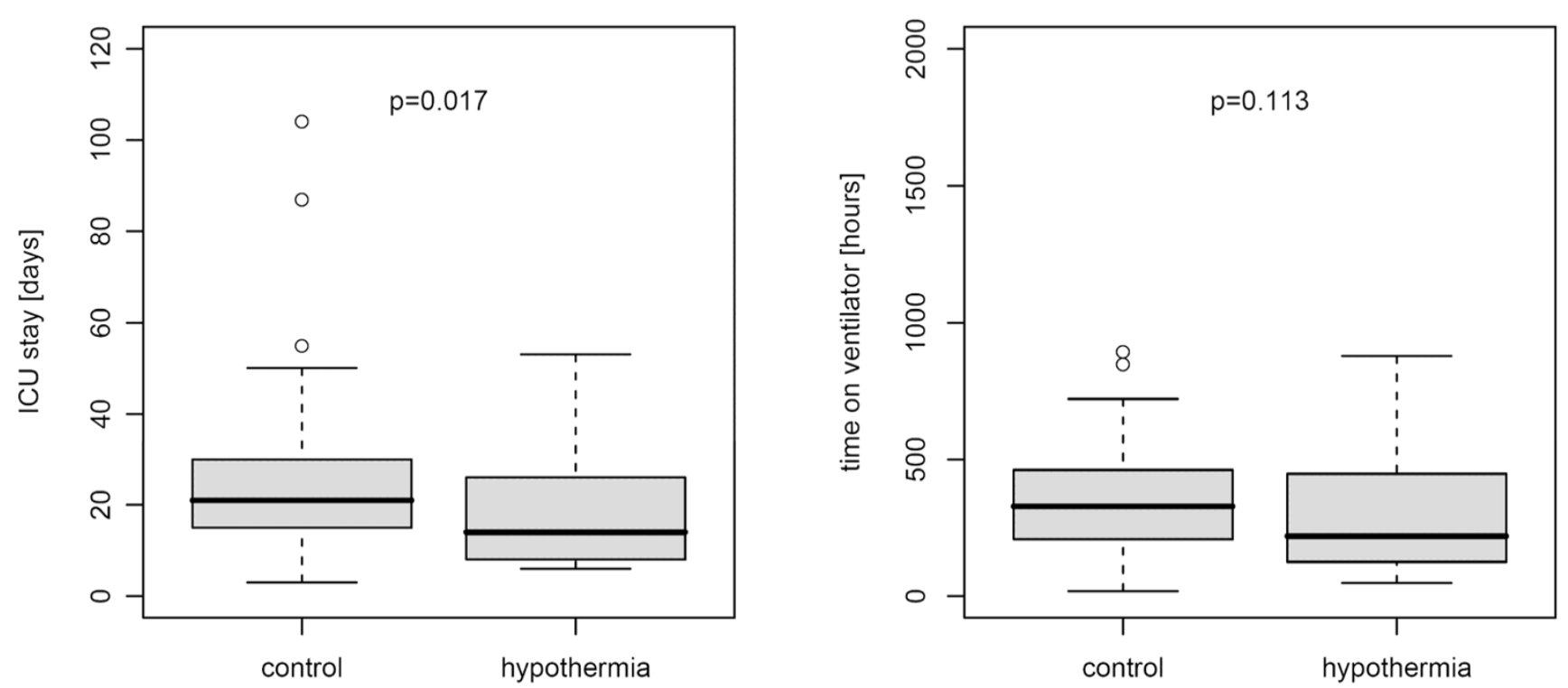

Intensive care unit (ICU) length of stay and time on ventilator in the study groups. Boxplot of ICU length of stay (left) and time on ventilator (right) in survivors of the hypothermia $(n=23)$ and the control $(n=43)$ group. 

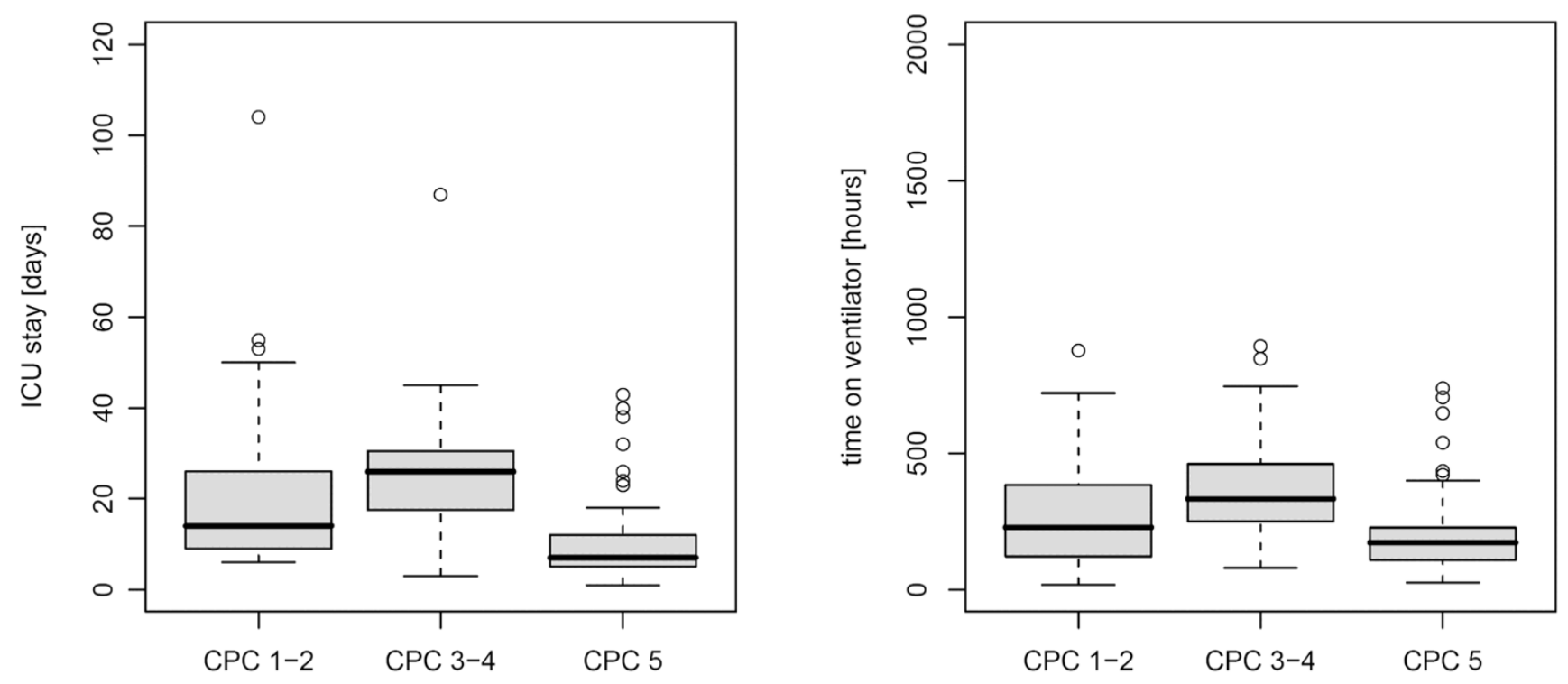

Intensive care unit (ICU) length of stay and time on ventilator and neurological outcome. Boxplot of ICU length of stay (left) and time on ventilator (right) of the study population ( $n=126$ ) according to the neurological outcome assessed as cerebral performance category (CPC).

time on mechanical ventilation. The complete results of the multivariate analyses are presented in Table 2. Follow-up data for 1-year survival probability were performed including all patients $(n=126)$. Kaplan-Meier analysis revealed a probability for 365 -day survival of $55.1 \%$ (confidence interval [Cl] $39.1 \%$ to $68.5 \%$ ) in the hypothermia group compared with $30.8 \%$ (Cl $19.9 \%$ to $42.3 \%)$ in the control group. The log-rank test was significant $(P=0.013)$ (Figure 3 ).

\section{Discussion}

Mild therapeutic hypothermia is recommended by current ILCOR guidelines and has become an essential part in postresuscitation care. Although the benefit concerning neurological outcome could not be demonstrated in a few single centers, most other trials could show an improved neurological outcome under hypothermia even in unselected effectiveness trials $[20,21]$. Nevertheless, technical, logistical, and financial barriers may limit the transfer into daily practice [22]. Therefore, for the first time, the present study investigates the impact of therapeutic hypothermia on ICU LOS in patients with out-ofhospital cardiac arrest. The major determinants of short ICU LOS and ventilator time in patients after cardiac arrest were found to be either early death during ICU stay or rapid neurological recovery. While comparison of all patients (survivors and non-survivors) did not reveal a statistical difference regarding ICU LOS, subgroup analysis showed that short ICU LOS is related to an improved neurological outcome in the hypothermia group. In contrast, short ICU LOS in the control group was associated with a high rate of non-survivors. This striking result was confirmed with a multivariate regression model emphasizing the impact of therapeutic hypothermia on ICU LOS.

A high APACHE II score at admission was associated with a prolonged ICU stay in our study. It seems plausible that patients with higher severity of illness depend more on critical care facilities; however, it is known that the predictive value of the APACHE II score has various limitations after cardiac arrest $[23,24]$. Our present results suggest that prognostic application of current scoring systems may be even more difficult in patients treated with therapeutic hypothermia. Both ICU LOS and time of mechanical ventilation tended to be longer in non-survivors of the hypothermia group compared with nonsurvivors of the control group, which may reflect the difficulty of outcome prediction in patients routinely requiring sedation and muscle relaxation in the first days of intensive care. Beside clinical evaluation, biochemical markers (neuron-specific enolase, protein S100B) and electrophysiological studies (somatosensory-evoked potentials) are established tools for outcome prediction in patients after cardiac arrest $[25,26]$. However, most of these parameters were studied in patients not undergoing hypothermia treatment. At present, little data on whether therapeutic hypothermia treatment may influence these biomarkers are available $[27,28]$. Therefore, physicians should be careful in the prognostication of patients treated with therapeutic hypothermia [29].

It should be mentioned that our analysis has various limitations. First of all, results obtained with an observational study design using a historical control group generally require further validation by a randomized controlled trial. However, ethical con- 
Table 2

\begin{tabular}{|c|c|c|c|c|}
\hline & Coefficient & $5 \% \mathrm{Cl}$ & $95 \% \mathrm{Cl}$ & $P$ value \\
\hline \multicolumn{5}{|l|}{ Start model (ICU LOS) } \\
\hline (Intercept) & 7.84 & -17.32 & 33.01 & 0.543 \\
\hline Gender female & -4.72 & -14.12 & 4.67 & 0.328 \\
\hline Age & 0.08 & -0.19 & 0.36 & 0.553 \\
\hline APACHE II score & 0.66 & 0.18 & 1.13 & 0.008 \\
\hline Hypothermia treatment & -10.63 & -17.93 & -3.32 & 0.006 \\
\hline Bystander CPR & -1.69 & -9.57 & 6.20 & 0.676 \\
\hline Ventricular fibrillation & 0.95 & -6.71 & 8.61 & 0.809 \\
\hline Time to ROSC & -0.12 & -0.73 & 0.49 & 0.706 \\
\hline \multicolumn{5}{|l|}{ Final model (ICU LOS) } \\
\hline (Intercept) & 10.80 & -0.64 & 22.24 & 0.068 \\
\hline APACHE II score & 0.63 & 0.19 & 1.07 & 0.006 \\
\hline Hypothermia treatment & -10.66 & -17.73 & -3.59 & 0.004 \\
\hline \multicolumn{5}{|c|}{ Start model (time on ventilator) } \\
\hline (Intercept) & 161.45 & -409.67 & 732.58 & 0.581 \\
\hline Gender female & 2.11 & -212.22 & 216.44 & 0.985 \\
\hline Age & 0.67 & -5.40 & 6.74 & 0.830 \\
\hline APACHE II score & 13.40 & 3.07 & 23.74 & 0.013 \\
\hline Hypothermia treatment & -182.72 & -342.75 & -22.69 & 0.028 \\
\hline Bystander CPR & -73.32 & -245.39 & 98.75 & 0.407 \\
\hline Time to ROSC & -5.16 & -19.03 & 8.71 & 0.469 \\
\hline Ventricular fibrillation & 22.19 & -145.07 & 189.46 & 0.780 \\
\hline \multicolumn{5}{|c|}{ Final model (time on ventilator) } \\
\hline (Intercept) & 107.25 & -142.68 & 357.17 & 0.403 \\
\hline APACHE II score & 13.07 & 3.58 & 22.57 & 0.009 \\
\hline Hypothermia treatment & -179.41 & -333.73 & -25.09 & 0.026 \\
\hline
\end{tabular}

Regression coefficients, associated confidence intervals, and $P$ values of start multiple regression model and final model after stepwise backward selection. Sign (- or + ) indicates negative or positive effect on the dependent variable. APACHE II, Acute Physiology and Chronic Health Evaluation II; Cl, confidence interval; CPR, cardiopulmonary resuscitation; ICU LOS, intensive care unit length of stay; ROSC, return of spontaneous circulation.

cerns will most likely prevent a further randomized trial that withholds hypothermia treatment from a control group. Second, our local treatment standards may have affected ICU LOS and patient outcome. There is considerable variation regarding end-of-life decisions and care practices. Thus, the approach used by a specific ICU on deciding whether to withhold or withdraw critical care in patients after cardiac arrest may have an important impact on ICU LOS. This may help to explain data from a Canadian survey reporting that patients with a higher Glasgow Coma Scale score had a longer ICU stay [30].
Moreover, differences in ICU LOS may also be related to a different use and allocation of ICU capacities in general. Decision making potentially may be influenced by a variety of factors that are independent of the individual patient characteristics, such as the availability of ICU beds and/or of facilities of 'step-down' care. It is of interest to note, however, that the necessity of mechanical ventilation, which is a rather objective criterion for the necessity of ICU treatment, is reduced by hypothermia treatment. Since impaired neurological status has been identified as a predictor of extubation failure or weaning failure [31,32], this finding may be associated with the more favorable neurological outcome in the hypothermia group. 
Figure 3

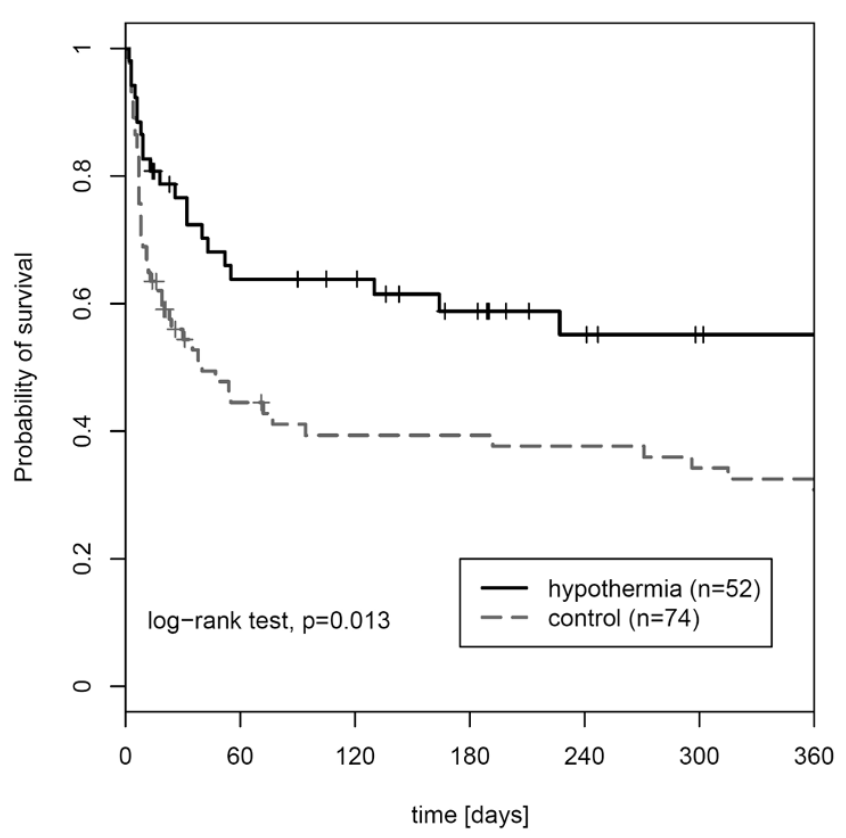

One-year survival of the study population. Kaplan-Meier 1-year survival analysis of both study groups.

Another issue with impact on ICU LOS and time on ventilator might be systemic inflammation after cardiac arrest. Both infectious and non-infectious systemic inflammations are a frequent problem in these patients [33,34]. As demonstrated in the HACA (Hypothermia after Cardiac Arrest) trial, there may even be a trend toward a higher rate of infections in patients treated with therapeutic hypothermia. However, we found no difference between the two study groups with respect to laboratory markers of inflammation (C-reactive protein/leukocyte count) and radiological findings of early-onset pneumonia. Therefore, early infection or pneumonia had no impact on different mechanical ventilator times between the groups.

In our analysis, we may have suffered from a selection bias because some baseline characteristics (bystander CPR and rate of ventricular fibrillation) tended to be more favorable in the hypothermia group although APACHE II score was lower in the control group. Finally, we cannot exclude the fact that the introduction of therapeutic hypothermia itself has focused the attention of the physicians in charge to a more sophisticated post-resuscitation care in general, which has been described [35]. However, similar promising results were also reported from a large hypothermia registry [36].

\section{Conclusion}

In summary, patients treated with therapeutic hypothermia showed both an impressive improvement of neurological outcome as well as an increased 1-year survival rate. Furthermore, therapeutic hypothermia did not prolong ICU stay or time of mechanical ventilation; rather, these parameters were reduced in survivors when therapeutic hypothermia was applied. Although we did not directly calculate the ICU treatment costs, we believe that this could be an additional argument for the application of therapeutic hypothermia in patients after cardiac arrest.

\section{Key messages}

- The major determinants of short intensive care unit (ICU) length of stay and ventilator time in patients after cardiac arrest were found to be either early death during ICU stay or rapid neurological recovery.

- Therapeutic hypothermia did not prolong ICU stay or time of mechanical ventilation in patients after cardiac arrest compared with historical controls.

- Both ICU stay and time of mechanical ventilation were reduced in survivors of cardiac arrest treated with therapeutic hypothermia.

- Therapeutic hypothermia was associated with significantly improved neurological outcome and 1-year survival.

\section{Competing interests}

The authors declare that they have no competing interests.

\section{Authors' contributions}

CS, IS, JCS, and DH designed and supervised the analysis and analyzed all data. MO was involved in the collection of all data and participated in the data analysis. AJ and AK participated in the design of the study, revised the manuscript for important intellectual content, and helped to draft the manuscript. CS and IS contributed equally to this work. All authors read and approved the final version of the manuscript.

\section{Acknowledgements}

We thank Astrid Caemmerer for assistance and support throughout the study.

\section{References}

1. Bulut S, Aengevaeren WR, Luijten HJ, Verheugt FW: Successful out-of-hospital cardiopulmonary resuscitation: what is the optimal in-hospital treatment strategy? Resuscitation 2000, 47:155-161.

2. Hypothermia after Cardiac Arrest Study Group: Mild therapeutic hypothermia to improve the neurologic outcome after cardiac arrest. N Engl J Med 2002, 346:549-556.

3. Bernard SA, Gray TW, Buist MD, Jones BM, Silvester W, Gutteridge G, Smith K: Treatment of comatose survivors of out-ofhospital cardiac arrest with induced hypothermia. N Engl J Med 2002, 346:557-563.

4. Nolan JP, Morley PT, Hoek TL Vanden, Hickey RW, Kloeck WG, Billi J, Böttiger BW, Morley PT, Nolan JP, Okada K, Reyes C, Shuster M, Steen PA, Weil MH, Wenzel V, Hickey RW, Carli P, Hoek TL Vanden, Atkins D, International Liaison Committee on Resuscitation: Therapeutic hypothermia after cardiac arrest: an advisory statement by the advanced life support task force of the International Liaison Committee on Resuscitation. Circulation 2003, 108:118-121.

5. Merchant RM, Soar J, Skrifvars MB, Silfvast T, Edelson DP, Ahmad F, Huang KN, Khan M, Hoek TL Vanden, Becker LB, Abella BS: 
Therapeutic hypothermia utilization among physicians after resuscitation from cardiac arrest. Crit Care Med 2006, 34:1935-1940.

6. Wolfrum S, Radke PW, Pischon T, Willich SN, Schunkert H, Kurowski V: Mild therapeutic hypothermia after cardiac arrest a nationwide survey on the implementation of the ILCOR guidelines in German intensive care units. Resuscitation 2007, 72:207-213.

7. Storm C, Schefold JC, Nibbe L, Martens F, Krueger A, Oppert M, Joerres A, Hasper D: Therapeutic hypothermia after cardiac arrest - the implementation of the ILCOR guidelines in clinical routine is possible! Crit Care 2006, 10:425.

8. Collins TJ, Samworth PJ: Therapeutic hypothermia following cardiac arrest: a review of the evidence. Nurs Crit Care 2008, 13:144-151.

9. Varon J, Acosta P: Therapeutic hypothermia: past, present, and future. Chest 2008, 133:1267-1274.

10. Bouch DC, Thompson JP, Damian MS: Post-cardiac arrest management: more than global cooling? $\mathrm{Br} J$ Anaesth 2008, 100:591-594.

11. Froehler MT, Geocadin RG: Hypothermia for neuroprotection after cardiac arrest: mechanisms, clinical trials and patient care. J Neurol Sci 2007, 261:118-126.

12. Holzer $M$, Behringer $W$, Schörkhuber $W$, Zeiner A, Sterz $F$ Laggner AN, Frass M, Siostrozonek P, Ratheiser K, Kaff A: Mild hypothermia and outcome after CPR. Hypothermia for Cardiac Arrest (HACA) Study Group. Acta Anaesthesiol Scand Suppl 1997, 111:55-58.

13. Zweifler RM, Voorhees ME, Mahmood MA, Alday DD: Induction and maintenance of mild hypothermia by surface cooling in non-intubated subjects. J Stroke Cerebrovasc Dis 2003, 12:237-243.

14. Flint AC, Hemphill JC, Bonovich DC: Therapeutic hypothermia after cardiac arrest: performance characteristics and safety of surface cooling with or without endovascular cooling. Neurocrit Care 2007, 7:109-118.

15. Merchant RM, Abella BS, Peberdy MA, Soar J, Ong ME, Schmidt GA, Becker LB, Hoek TL Vanden: Therapeutic hypothermia after cardiac arrest: unintentional overcooling is common using ice packs and conventional cooling blankets. Crit Care Med 2006, 34:S490-S494.

16. Kim F, Olsufka M, Carlbom D, Deem S, Longstreth WT Jr, Hanrahan M, Maynard C, Copass MK, Cobb LA: Pilot study of rapid infusion of $\mathbf{2} \mathrm{L}$ of 4 degrees $\mathrm{C}$ normal saline for induction of mild hypothermia in hospitalized, comatose survivors of outof-hospital cardiac arrest. Circulation 2005, 112:715-719.

17. Uray T, Malzer R: Out-of-hospital surface cooling to induce mild hypothermia in human cardiac arrest: A feasibility trial. Resuscitation 2008, 77:331-338.

18. Jakobsson J, Nyquist $O$, Rehnqvist $N$, Norberg KA: Cost of a saved life following out-of-hospital cardiac arrest resuscitated by specially trained ambulance personnel. Acta Anaesthesiol Scand 1987, 31:426-429.

19. Jennett $B$, Bond $M:$ Assessment of outcome after severe brain damage. Lancet 1975, 1:480-484.

20. Bekkers SC, Eikemans BJ, Tieleman R, Braat SH, Dassen W, Partouns J, de Zwaan C, Crijns HJ, de Krom MC: Hypothermia for out-of-hospital cardiac arrest survivors: a single-center experience. Am J Emerg Med 2007, 25:1078-1080.

21. Oddo M, Schaller MD, Feihl F, Ribordy V, Liaudet L: From evidence to clinical practice: effective implementation of therapeutic hypothermia to improve patient outcome after cardiac arrest. Crit Care Med 2006, 34:1865-1873.

22. Soreide E, Sunde K: Therapeutic hypothermia after out-of hospital cardiac arrest: how to secure worldwide implementation. Curr Opin Anaesthesiol 2008, 21:209-215.

23. Niskanen $M$, Kari A, Nikki $P$, lisalo $E$, Kaukinen $L$, Rauhala $V$, Saarela E, Halinen M: Acute physiology and chronic health evaluation (APACHE II) and Glasgow coma scores as predictors of outcome from intensive care after cardiac arrest. Crit Care Med 1991, 19:1465-1473.

24. Nolan JP, Laver SR, Welch CA, Harrison DA, Gupta V, Rowan K: Outcome following admission to UK intensive care units after cardiac arrest: a secondary analysis of the ICNARC Case Mix Programme Database. Anaesthesia 2007, 62:1207-1216.

25. Grubb NR, Simpson C, Sherwood RA, Abraha HD, Cobbe SM, O'Carroll RE, Deary I, Fox KA: Prediction of cognitive dysfunc- tion after resuscitation from out-of-hospital cardiac arrest using serum neuron-specific enolase and protein S-100. Heart 2007, 93:1268-1273.

26. Carter BG, Butt W: Review of the use of somatosensory evoked potentials in the prediction of outcome after severe brain injury. Crit Care Med 2001, 29:178-186.

27. Tiainen M, Roine RO, Pettila V, Takkunen O: Serum neuron-specific enolase and S-100B protein in cardiac arrest patients treated with hypothermia. Stroke 2003, 34:2881-2886.

28. Sunde $K$, Dunlop O, Rostrup M, Sandberg M, Sjoholm H, Jacobsen D: Determination of prognosis after cardiac arrest may be more difficult after introduction of therapeutic hypothermia. Resuscitation 2006, 69:29-32.

29. Geocadin RG, Eleff SM: Cardiac arrest resuscitation: neurologic prognostication and brain death. Curr Opin Crit Care 2008, 14:261-268.

30. Keenan SP, Dodek P, Martin C, Priestap F, Norena M, Wong H: Variation in length of intensive care unit stay after cardiac arrest: where you are is as important as who you are. Crit Care Med 2007, 35:836-841.

31. Namen AM, Ely EW, Tatter SB, Case LD, Lucia MA, Smith A, Landry S, Wilson JA, Glazier SS, Branch CL, Kelly DL, Bowton DL, Haponik EF: Predictors of successful extubation in neurosurgical patients. Am J Respir Crit Care Med 2001, 163:658-664.

32. Salam A, Tilluckdharry L, Amoateng-Adjepong Y, Manthous CA: Neurologic status, cough, secretions and extubation outcomes. Intensive Care Med 2004, 30:1334-1339.

33. Tsai MS, Chiang WC, Lee CC, Hsieh CC, Ko PC, Hsu CY, Su CP, Chen SY, Chang WT, Yuan A, Ma MH, Chen SC, Chen WJ: Infections in the survivors of out-of-hospital cardiac arrest in the first 7 days. Intensive Care Med 2005, 31:621-626.

34. Adrie C, Laurent I, Monchi M, Cariou A, Dhainaou JF, Spaulding C: Postresuscitation disease after cardiac arrest: a sepsis-like syndrome? Curr Opin Crit Care 2004, 10:208-212.

35. Sunde K, Pytte M, Jacobsen D, Mangschau A, Jensen LP, Smedsrud C, Draegni T, Steen PA: Implementation of a standardised treatment protocol for post resuscitation care after out-ofhospital cardiac arrest. Resuscitation 2007, 73:29-39.

36. Arrich J: Clinical application of mild therapeutic hypothermia after cardiac arrest. Crit Care Med 2007, 35:1041-1047. 